\title{
RANCANG BANGUN MESIN PENGGILING BIJI JARAK
}

\author{
Wirda Novarika \\ Jurusan Teknik Mesin Politeknik Negeri Sriwijaya \\ Jl. Sriwijaya Negara Bukit besar Palembang 30139 \\ Telp: 0711-353414, Fax: 0711-453211
}

\begin{abstract}
The latest of Fuel's Crisis makes us to find out another alternative material to be as a new fuel. One of them is Biji Jarak Pagar. Wher it's choser as the selected material because of its more strength. But, the existing process is by hand-made (manual), so it would make the process's not effective and efficient. The purpose of this final report is to learn how to process them being a fuel well. The data were collecte then analysed to make a new machine. So, it will be gotten Alat Penggiling Buji Jarak. Where it can be used to break them more effective and efficient.
\end{abstract}

\section{Keyword : Effective Process, efficient process}

\section{PENDAHULUAN}

Krisis BBM fosil akhir-akhir ini mendorong pencarian sumber bahan bakar alternatif terbarukan. Sumber bahan bakar alternatif itu antara lain berupa tanaman. Bahan bakar dari tanaman yang dikembangkan sesuai blue print pengelolaan energi nasional adalah biodiesel, bioetanaol (gasohol), dan bio-oil. Biodiesel adalah bahan bakar untuk mesin-mesin diesel. Gasohol untuk mesin-mesin berbahan bakar bensin. Sementara, bio-oil adalah pengganti bahan bakar atau minyak tanah.

Biodiesel dapat dibuat dari minyak mentah kelapa sawit (Crude Palm Oil atau CPO), minyak biji jarak pagar, minyak kelapa, dan tanaman lainnya. Beberapa tanaman yang potensial untuk menghasilkan biofuel (bahan bakar yang dibuat dari bahan tanaman) dapat dilihat pada tabel.
Tabel 1. Berbagai Tanaman Penghasil Biofuel

\begin{tabular}{|c|c|c|c|}
\hline Nama & $\begin{array}{c}\text { Produksi } \\
\text { tanaman } \\
\text { tanaman }\end{array}$ & $\begin{array}{c}\text { Produksi } \\
\text { Biofuel } \\
\text { (Liter/ha) }\end{array}$ & $\begin{array}{c}\text { Energi } \\
\text { Ekivalen } \\
\text { (Kwh/ha) }\end{array}$ \\
\hline $\begin{array}{c}\text { Kelapa } \\
\text { sawit }\end{array}$ & $18-20$ & $\begin{array}{c}3.600- \\
4.000\end{array}$ & $\begin{array}{c}33.900- \\
37.700\end{array}$ \\
\hline Jarak & $6-8$ & $\begin{array}{c}2.100- \\
2.800\end{array}$ & $\begin{array}{c}19.800- \\
26.400\end{array}$ \\
pagar & & $1.800-$ & $17.000-$ \\
2.700 & 25.500 \\
\hline Tebu & 35 & $\begin{array}{c}1.200- \\
2.000\end{array}$ & $11.300-$ \\
& & 1.020 & 6.600 \\
\hline Jarak & $3-5$ & & \\
kepyar & & & \\
\hline Ketela & 6 & & \\
pohon & & &
\end{tabular}

Akan tetapi, untuk memilih jenis bahan baku biofuel diperlukan pertimbangan yang matang. Jarak pagar merupakan pilihan tepat. Alasannya, tanaman ini merupakan bahan pangan dan mudah ditanam di berbagai lahan, termasuk lahan kritis. Budi daya tanaman jarak juga tidak memerlukan biaya yang tinggi dan bijinya cepat dipanen. 
Biji jarak mengandung minyak lebih dari $40 \%$. Pengolahan biji jarak ini menjadi minyak jarak mentah dapat dilakukan dengan cara sederhana sehingga dapat menjadi sumber pendapatan baru bagi petani.

Minyak jarak mentah dimurnikan menjadi minyak jarak murni (pure jatropha oil) dengan cara menghilangkan kandungan lemak dan gum di dalamnya. Minyak jarak alami ini dapat langsung digunakan langsung tanpa proses lanjutan. Misalnya untuk mengoperasikan mesin genset dan dan mesin pembangkit listrik. Selain itu juga dapat digunakan sebagai minyak bakar, seperti untuk kompor, penghangat bibit ayam boiler, dan lampu penerangan.

Untuk membuat biodiesel, minyak jarak murni diolah dengan teknologi trans-esterifikasi menggunakan etanol atau methanol. Biodiesel murni dapat digunakan sebagai pengganti minyak diesel atau solar maupun dicampur dengan solar untuk bahan bakar kendaraan bermesin diesel.

Keuntungan penggunaan minyak jarak adalah dapat menjaga kebersihan lingkungan. Emisi gas sulfur $\left(\mathrm{So}_{\mathrm{x}}\right)$, nitrogen $\left(\mathrm{NO}_{\mathrm{x}}\right)$, dan karbon dari pembakaran minyak jarak yang mencemari udara lebih kecil dibandingkan minyak solar dari bahan bakar fosil.

Berangkat dari persoalan pemenuhan kebutuhan bahan bakar biodiesel di atas, maka penulis mencoba merancang suatu alat bantu sederhana penggiling biji jarak. Alat bantu sederhana ini penulis sebutkan "MESIN PENGGILING BIJI JARAK".

\section{TINJAUAN PUSTAKA}

\section{Kriteria Pemilihan Bahan}

Pada setiap perencanaan suatu peralatan bahan, harus ada pertimbangan pemilihan bahan yang merupakan suatu syarat penting sebelum melakukan perhitungan terhadap kekuatan dari komponenkomponen yang direncanakan tersebut. Selain itu pemilihan bahan juga harus sesuai dengan kemampuan, serta fungsi bebanbeban yang diterima oleh tiap-tiap komponen yang terdapat pada peralatan tersebut. Adapun tujuan pemilihan bahan tersebut adalah agar bahan yang direncanakan tersebut dapat ditekan seefisien mungkin pemakaiannya, selain itu bahan tersebut diharapkan dapat menahan beban yang diterimanya lebih baik. Hal yang perlu diperhatikan sebagai faktor dan pertimbangan pemilihan bahan adalah:

1. Penggunaan bahan yang efisien, tetapi tidak mengurangi kemampuan dan fungsi dari komponen peralatan yang direncanakan.

2. Bahan tersebut mudah didapat di pasaran.

3. Mempunyai kekuatan yang cukup terhadap beban yang diterimanya.

4. Harga barang tersebut relatif murah.

5. Untuk komponen-komponen tertentu harus tahan terhadap korosi dan keausan.

Tetapi di dalam prakteknya, jarang sekali didapatkan bahan dengan sifat dan karakteristik seperti di atas. Dalam hal ini mempertimbangkan kekuatan suatu bahan perlu diusahakan agar jenis bahan yang dipergunakan tidak terlalu bervariasi.

\section{Nama-nama Bagian Mesin \\ Penggiling}

\section{Pisau Penggiling}

Berfungsi menggiling bahan baku biji jarak yang ingin dipergunakan. Gilingan ini direncanakan dibuat dari bahan baja yang tahan karat sehingga hasil gilingan bersih.

\section{Motor Listrik}

Motor listrik sebagai penghasil daya yang digunakan untuk 
menggerakkan poros yang terhubung ke pisau penggiling.

3. Poros Berulir

Merupakan komponen mesin yang berputar, digunakan untuk mentransformasi atau memindahkan daya dari satu bagian ke bagian lain. Oleh karena itu, bahan yang dipakai harus mempunyai kekuatan yang melebihi beban yang terjadi. Dalam perencanaan ini digunakan 1 buah poros dengan bahan yang sama yaitu ST 42 dengan kekuatan tarik $42 \mathrm{~kg} / \mathrm{mm}^{2}$.

4. Pasak

Merupakan bagian dari mesin yang berfungsi menetapkan bagian mesin yang berputar dengan poros. Oleh karena itu pasak dibuat dari bahan yang lebih lunak dari bahan poros, dengan tujuan agar pasak lebih mudah rusak bila terjadi pergeseran atau gesekan dengan bagian mesin yang ditahannya. Hal ini terjadi karena pasak lebih mudah dibuat dan diperbaiki, bahan pasak mempergunakan ST 37 dengan kekuatan tarik 37 $\mathrm{kg} / \mathrm{mm}^{2}$.

5. Pulley dan Sabuk

Digunakan untuk mentransmisikan daya dan putaran dari motor listrik. Sabuk yang dipakai dalam perencanaan ini adalah sabuk tipe $\checkmark$ yang diambil dari standar Pulley Benzeller.

6. Bantalan

Bantalan direncanakan untuk menerima beban radial, beban aksial atau gabungan keduanya.Berfungsi untuk menumpu poros yang berputar dan menghaluskan putaran poros.

7. Kerangka Mesin

Kerangka mesin mempunyai fungsi untuk menahan berat seluruh komponen yang terdapat pada mesin penggiling biji jarak. Oleh karena itu penulis menggunakan kerangka profil "L" sebab selain material ini mudah didapat di 'pasaran, juga mempunyai kekuatan yang cukup untuk menahan beban dari komponenkomponen yang telah direncanakan.

\section{RANCANG BANGUN \\ Menghitung Gaya Pemecahan Biji Jarak}

Sebelum memulai perencanaan, pertama kali dilakukan pengujian terhadap biji jarak dengan tujuan untuk mengetahui besarnya gaya yang dibutuhkan untuk menghancurkan biji jarak tersebut. Adapun kriteria biji jarak yang digunakan adalah biji jarak yang sudah dikeringkan dan sudah dipisahkan dari cangkangnya.

Berikut ini beberapa urutan prosedur yang dilakukan dalam pengujian :

1. Siapkan pisau potong, timbangan, stopwatch dan 5 buah biji jarak yang telah dikupas

2. Biji jarak diletakkan di atas timbangan

3. Letakkan pisau dalam keadaan siap memotong lalu tekan pisau memotong biji jarak

4. Amati gaya yang dihasilkan yang bisa dilihat dari jarum pada timbangan dan catat waktu yang diperlukan untuk memotong biji jarak.

Untuk lebih jelasnya dapat dilihat pada gambar di bawah ini :

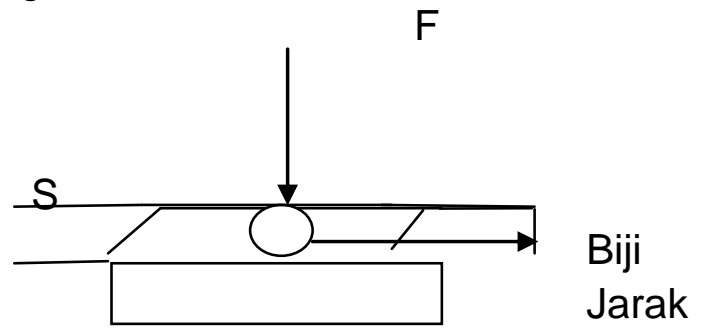

Gambar 1.

Percobaan pemotongan biji jarak 
Tabel 2. Dari 5 kali pengujian didapatkan data-data sebagai berikut :

\begin{tabular}{|c|c|c|c|}
\hline Pengujian & Gaya F $(\mathrm{kg})$ & Waktu T (detik) & Tebal S $(\mathrm{mm})$ \\
\hline 1 & 2,5 & 0,57 & 8 \\
\hline 2 & 2 & 1,5 & 7 \\
\hline 3 & 2,5 & 1,26 & 9 \\
\hline 4 & 1,5 & 0,96 & 7 \\
\hline 5 & 2 & 1,44 & 8 \\
\hline
\end{tabular}

Dengan asumsi setiap pisau dapat memotong 5 biji jarak sedangkan yang digunakan ada 4 buah pisau. Maka

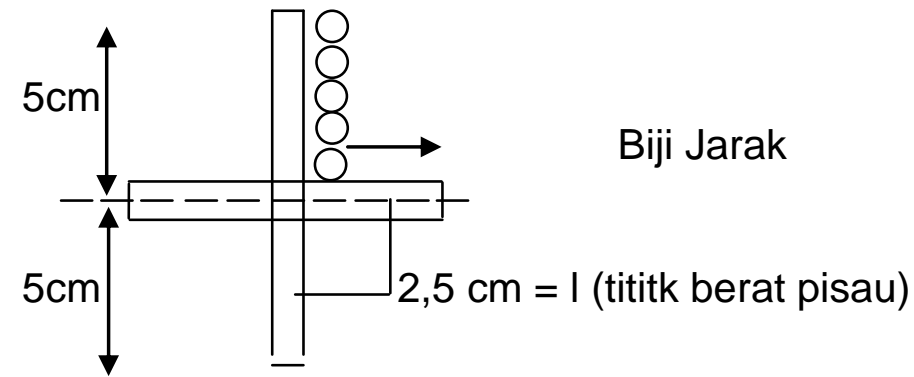

Gaya (F) untuk satu pisau per biji jarak $=2,5 \mathrm{Kg} \times 10 \mathrm{~m} / \mathrm{s}=25 \mathrm{~N}$

\section{Pisau Penggiling}

\section{Bahan Pisau Penggiling}

Perencanaan ini menggunakan Pisau penggiling yang berfungsi menghancurkan biji jarak yang telah dikupas. Untuk lebih jelasnya dapat dilihat dari gambar berikut :
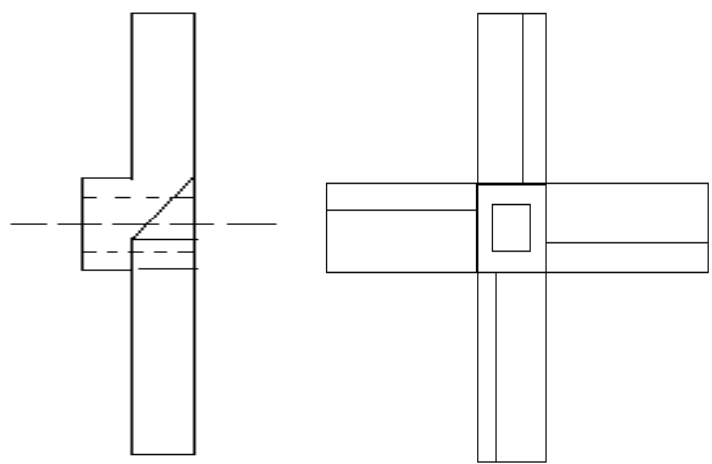

Gambar 2

Pisau Penggiling

Bahan dari Pisau penggiling ini diambil baja karbon ST 60 dengan kekuatan tarik $60 \mathrm{Kg} / \mathrm{mm}^{2}$.

Faktor keamanan Sf1 $=6$

$$
\text { Sf2 }=2
$$

besar gaya yang dibutuhkan unuk satu pisau $=2,5 \mathrm{Kg}$ (diambil yang terbesar).

Tebal 1 biji jarak $0,9 \mathrm{~cm}$ panjang 1 pisau $4 \mathrm{~cm}$
Maka gaya untuk 5 biji jarak/ pisau $=5 \times 25=125 \mathrm{~N}$
Panjang Pisau Penggiling $\quad=87 \mathrm{~mm}$ maka Tegangan Geser izin adalah

$$
\begin{aligned}
T_{\text {izin }} & =\frac{T_{b}}{S f 1 \times S f 2} \\
T_{\text {izin }} & =\frac{60 \mathrm{~kg} / \mathrm{mm}^{2}}{6.2}=5 \mathrm{Kg} / \mathrm{mm}^{2}
\end{aligned}
$$

\section{Momen Puntir Pada Pisau Penggiling}

Untuk menghitung momen puntir pada pisau penggiling dapat digunakan persamaan :

$$
T=F x l
$$

Dimana

$\mathrm{T}=$ Momen puntir pada pisau penggiling (Kgmm)

$\mathrm{F}=$ Gaya Potong rata-rata $(\mathrm{Kg})$

$\mathrm{L}=$ Panjang Pisau penggiling $(\mathrm{mm})$ diambil berdasarkan titik berat pisau

Maka Momen puntir untuk satu pisau : $T=125 \mathrm{~N} x 2,5=312,5 \mathrm{Ncm}=3,125 \mathrm{Nm}$ 
Momen puntir untuk 4 pisau :

$$
\begin{aligned}
& \mathrm{T}_{\text {Total }}=4 \times 3,125 \mathrm{Nm} \\
& \mathrm{T}_{\text {Total }}=12,5 \mathrm{Nm}
\end{aligned}
$$

Poros

\section{Bahan Poros}

Untuk poros ini direncanakan menggunakan bahan ST 42 dengan kekuatan tarik $42 \mathrm{Kg} / \mathrm{mm}^{2}$. Dengan Faktor keamanan $\mathrm{Sf} 1=6, \mathrm{Sf} 2=2$. Maka Tegangan geser Izin adalah :

$$
\begin{aligned}
T_{\text {izin }} & =\frac{T_{b}}{S f 1 \times S f 2} \\
T_{\text {izin }} & =\frac{42 \mathrm{~kg} / \mathrm{mm}^{2}}{6.2}=3,5 \mathrm{Kg} / \mathrm{mm}^{2}
\end{aligned}
$$

\section{Diameter Poros}

Diameter Poros dapat ditentukan dengan menggunakan persamaan berikut :

$$
\mathrm{ds}^{3}=\frac{5,1}{\mathrm{~T}_{\mathrm{izin}}} \mathrm{Cb} . \mathrm{Kt} . \mathrm{T}
$$

Dimana

$$
\begin{array}{rll}
\mathrm{ds} & = & \text { Diameter poros }(\mathrm{mm}) \\
\tau_{i z i n} & = & \text { Tegangan Geser izin } \\
& \text { bahan poros }\left(\mathrm{Kgmm}^{2}\right) \\
\mathrm{Cb} & = & \text { Faktor koreksi beban } \\
\mathrm{Kt} & =\begin{array}{l}
\text { Lenturan }(1,2-2,3) \\
\text { Faktor koreksi beban }
\end{array} \\
\mathrm{T} & \begin{array}{l}
\text { puntiran }(1,0-1,5) \\
\text { Momen Puntir Poros } \\
\text { (Kgmm) }
\end{array}
\end{array}
$$

Sebelum menghitung diameter poros, hitung dahulu Torsi pada poros dengan persamaan.tDimana

$\mathrm{T}=$ Torsi/momen puntir poros (Kgmm) $\quad P d=$ Daya Rencana (Watt)

$\mathrm{n}=$ Putaran mesin (Rpm)

Untuk mengetahui Daya output dapat dicari dengan persamaan sebagai berikut :

$$
\mathrm{P}=\operatorname{Tx} \omega
$$

Dimana $P=$ Daya Output (Watt)

$$
\mathrm{T}=\text { Torsi pada pisau (Nm) }
$$

$\omega=$ Kecepatansudut $\rightarrow$ diasumsikan

6 putaran per detik

$$
\omega=2 \pi m=2 \times 3,14 \times 6=37,68 \mathrm{rad} / \mathrm{s}
$$

Sehingga

$$
\begin{gathered}
P=T_{\text {Total }} \times \omega \\
P=12,5 \times 37,68=471 \text { Watt }= \\
0,471 \text { KWatt }
\end{gathered}
$$

Dari persamaan-persamaan di atas, selanjutnya masukkan data-data yang diperoleh :

- Daya yang dibutuhkan $=0,471$ KWatt

-Daya'Rencana'Lit 1. Bąly $\mathrm{x}$ faktor koreksi $(1,2-2,0)$

$=0,471 \times 1,2$

$=0,5652 \mathrm{KWatt}$

- $\mathrm{T}=9,74 \cdot 10^{5} \frac{0,5652 \mathrm{KWatt}}{1450}=380 \mathrm{Kgmm}$

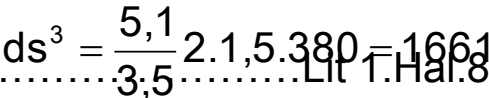

$$
\mathrm{ds}=\sqrt[3]{1661}=11,84 \mathrm{~mm}
$$

Diameter 11,9 mm sudah aman tetapi dipakai Diameter $17 \mathrm{~mm}$

Pasak

\section{Bahan Pasak}

Untuk pasak ini direncanakan menggunakan bahan ST 37 dengan kekuatan tarik $37 \mathrm{Kg} / \mathrm{mm}^{2}$. Dengan Faktor keamanan $\mathrm{Sf} 1=6, \mathrm{Sf} 2=2$. Maka Tegangan geser Izin adalah :

$$
\begin{aligned}
\mathrm{T}_{\mathrm{izin}} & =\frac{\mathrm{T}_{\mathrm{b}}}{\mathrm{Sf1} 1 \mathrm{Sf} 2} \\
\mathrm{~T}_{\text {izin }} & =\frac{37 \mathrm{~kg} / \mathrm{mm}^{2}}{6.2}=3,08 \mathrm{Kg} / \mathrm{mm}^{2}
\end{aligned}
$$

\section{Ukuran Penampang Pasak}

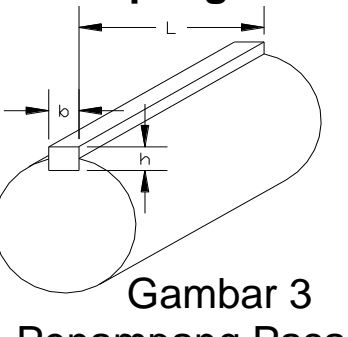

Penampang Pasak 
Berdasarkan tabel standar ukuran pasak untuk poros Diameter 17 $22 \mathrm{~mm}$ didapat data-data sebagai berikut :

o $\mathrm{b}=6 \mathrm{~mm}$

$\circ \mathrm{h}=6 \mathrm{~mm}$

○ $\mathrm{L}=14-70 \mathrm{~mm}$, L pasak $0,75-1,5 \mathrm{ds}$

$=1,5 \times 17=25,5$

$=25,5 \mathrm{~mm}$

\section{Gaya Tangensial Pada Permukaan} Pasa

Gaya Tangensial pada permukaan pasak dapat ditentukan dengan persamaan sebagai berikut:

$$
\mathrm{Ft}=\frac{\mathrm{T}}{\mathrm{ds} / 2}
$$

Dimana

$\mathrm{Ft}=$ Gaya Tangensial pada permukaan

$$
\text { pasak }(\mathrm{Kg})
$$

$\mathrm{T}=$ Torsi pada poros (Kgmm)

$\mathrm{ds}=$ Diameter poros $(\mathrm{mm})$

Sehinga

$$
\mathrm{Ft}=\frac{380 \mathrm{Kgmm}}{17 / 2}=44,7 \mathrm{Kg}
$$

\section{Kerusakan akibat Tegangan Geser}

Kerusakan akibat tegangan Geser dapat ditentukan dengan persamaan sebagai berikut:

$$
T_{g}=\frac{F t}{b . L}
$$

Dimana

$$
\begin{aligned}
\tau_{g}= & \text { Tegangan geser }\left(\mathrm{Kg} / \mathrm{mm}^{2}\right) \\
\mathrm{Ft}= & \text { Gaya Tangensial pada } \\
& \text { permukaan pasak }(\mathrm{Kg}) \\
\mathrm{b}= & \text { Tebal Pasak }(\mathrm{mm}) \\
\mathrm{L}= & \text { Panjang Pasak }(\mathrm{mm})
\end{aligned}
$$

Sehingga

$$
\mathrm{T}_{\mathrm{g}}=\frac{44,7 \mathrm{Kg}}{6.25}=0,298 \mathrm{Kg} / \mathrm{mm}^{2}
$$

\section{Tekanan Permukaan Pasak}

Tekanan permukaan pasak dapat ditentukan dengan persamaan sebagai berikut :

$$
\mathrm{Pa}=\frac{\mathrm{Ft}}{\mathrm{L} .\left(\mathrm{t}_{1}-\mathrm{t}_{2}\right)}
$$

Dimana

$$
\begin{aligned}
\mathrm{Pa}= & \text { Tekanan Pasak }\left(\mathrm{Kg} / \mathrm{mm}^{2}\right) \\
\mathrm{Ft}= & \text { Gaya Tangensial pada } \\
& \text { permukaan pasak }(\mathrm{Kg}) \\
\mathrm{t}_{1}= & \text { Kedalaman alur pasak pada } \\
& \text { poros }(\mathrm{mm}) \\
\mathrm{t}_{2}= & \text { Kedalaman alur pasak pada } \\
& \text { naf }(\mathrm{mm}) \\
\mathrm{L}= & \text { Panjang Pasak }(\mathrm{mm})
\end{aligned}
$$

sehingga

$\mathrm{Pa}_{1}=\frac{44,7 \mathrm{Kg}}{25 \cdot 3,5}=0,51 \mathrm{Kg} / \mathrm{mm}^{2}$

$\mathrm{Pa}_{2}=\frac{44,7 \mathrm{~g}}{25 \cdot 2,8}=0,638 \mathrm{Kg} / \mathrm{mm}^{2}$

Harga $\mathrm{Pa}$ untuk diameter kecil $=8$ $\mathrm{Kg} / \mathrm{mm}^{2}$. Karena harga $\mathrm{Pa}_{1}$ dan $\mathrm{Pa}_{2}$ lebih kecil dari yang distandarkan, maka pasak dinyatakan aman.

\section{Pulley dan Sabuk}

Untuk memindahkan daya dari motor penggerak ke poros mesin yang digerakkan, mesin ini menggunakan sistem pemindah daya sabuk dan pulley. Dari perhitungan daya motor didapat $0,5652 \mathrm{KW}$ att $\rightarrow 0,75$ hp pada putaran $1450 \mathrm{Rpm}$.

\section{Pemilihan Pulley}

Daya motor $(P)=0,5652 \mathrm{KWatt}$

Putaran motor penggerak

$$
\left(n_{1}\right)=1450 \mathrm{rpm}
$$

Putaran mesin yang digerakkan

$$
\left(\mathrm{n}_{2}\right)=50 \mathrm{rpm}
$$

Putaran mesin yang direncanakan

$$
\left(n_{2}\right)=50 \mathrm{rpm}
$$

Sehingga perbandingan putarannya :

$$
\begin{aligned}
& i=\frac{n_{1}}{n_{2}} \\
& i=\frac{1450 R p m}{50 R p m}=29
\end{aligned}
$$

Karena perbandingan pulley penggerak dan yang digerakkan sangat besar 29 : 1, maka untuk menghindari penggunaan pulley 
ukuran besar kami memakai speed reducer yang memiliki perbandingan putaran yang sama $29: 1$.

Berdasarkan standar dari motor listrik, maka dapat dipilih pulley dengan spesifikasi :

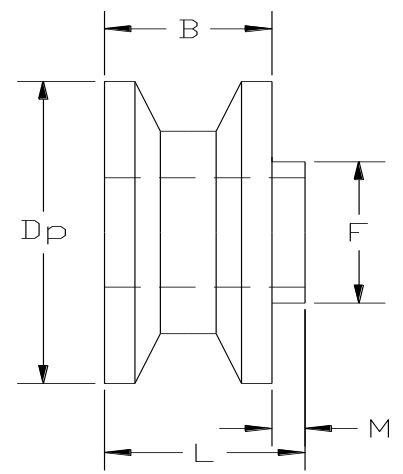

Gambar 4 Pulley

Diameter pulley Penggerak $(\mathrm{Dp})=63$ $\mathrm{mm}$

Diameter step $(F)=60 \mathrm{~mm}$

$$
\begin{aligned}
\text { Lebar }(B) & =L-M \\
& =22-6 \\
& =16 \mathrm{~mm} \\
\text { Berat } & =0,27 \mathrm{Kg}
\end{aligned}
$$

Untuk mendapat putaran yang sesuai, maka Spesifikasi pulley yang digerakkan sama dengan pulley penggerak.

\section{Pemilihan Sabuk}

Dari perhitungan daya rencana 0,5652KWatt dan putaran motor1450rpm, maka dapat ditentukan tipe sabuk yang sesuai. Berdasarkan diagram pemilihan sabuk-V, maka untuk daya rencana 0,5652KWatt sabuk yang dipakai adalah $\mathrm{V}$ Tipe $\mathrm{A}$.

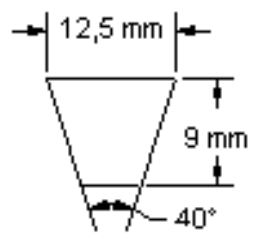

Gambar 5

Penampang Sabuk
Jarak Sumbu pulley direncanakan 500 $\mathrm{mm}$ sehingga panjang sabuk:

$L=2 x C+\pi / 2\left(D p_{1}+D p_{2}\right)+1 / 4 x C\left(D p_{1}+D p_{2}\right)^{2}$

$\mathrm{L}=2 \times 500+3,14 / 2(63+63)+1 / 4 \times C(63-63)^{2}$

$\mathrm{L}=1000+197,82+0$

$\mathrm{L}=1197,2 \mathrm{~mm}$

\section{Besar Sudut Kontak Pulley dengan} sabuk

Besar sudut kontak antara pulley dengan sabuk $(\theta)$ dapat dicari dengan persamaan berikut :

$\theta=180^{\circ}-\frac{57(\mathrm{Dp}-\mathrm{dp})}{\mathrm{C}}$

Dimana

$\mathrm{Dp}=$ Diameter pulley penggerak $(\mathrm{mm})$

$\mathrm{dp}=$ Diameter pulley yang

digerakkan

$\mathrm{C}=$ Jarak sumbu pulley $(\mathrm{mm})$

Sehingga

$$
\begin{array}{ll}
\theta=180^{\circ}-\frac{57(63-63)}{500} & \theta=\frac{\pi}{180} \times 180^{\circ} \\
\theta=180^{\circ} & \theta=3,14 \mathrm{rad}
\end{array}
$$

\section{Besar Tegangan Sabuk}

Besar tegangan sabuk dapat diketahui dngan menggunakan persamaan sebagai berikut :

$$
\mathrm{P}=\left(\mathrm{T}_{1}-\mathrm{T}_{2}\right) \mathrm{V}
$$

Dimana

$$
\mathrm{P}=\text { Daya Motor (KWatt) }
$$

$\mathrm{T}_{1}=$ Tegangan sabuk sisi kencang $(\mathrm{Kg})$

$\mathrm{T}_{2}=$ Tegangan sabuk sisi kendur $(\mathrm{Kg})$

$$
\mathrm{V}=\quad \text { Kecepatan putaran }
$$
(m/detik)(m/menit)

Untuk menyelesaikan persamaan di atas, lengkapi variabel-variabel perhitungan yang dibutuhkan.

Menentukan kecepatan putaran :

$$
\frac{\mathrm{Fa}}{\mathrm{V} . \mathrm{Fr}}=\frac{44 \mathrm{Kg}}{1 \times 21,656 \mathrm{Kg}}=2,03
$$




$$
\begin{aligned}
& V=\frac{3,14 \times 63 \times 50}{60000} \\
& V=0,16485 \mathrm{~m} / \mathrm{dt} \\
& \mathrm{V}=9,891 \mathrm{~m} / \mathrm{menit}
\end{aligned}
$$

Menentukan salah satu Tegangan sabuk $\left(\mathrm{T}_{2}\right)$ :

Dimana

$$
\begin{aligned}
\mu= & \text { Koefisien gesek sabuk } \\
\theta= & \begin{array}{c}
\text { Besar sudut kontak pulley } \\
\text { dengan } \\
\text { sabuk }
\end{array} \\
\frac{\mathrm{T}_{1}}{\mathrm{~T}_{2}}= & \text { Besar tegangan sabuk }(\mathrm{Kg})
\end{aligned}
$$

Menentukan koefisien gesek sabuk:

$$
\begin{aligned}
& \mu=0,54-\frac{42,6}{152,6+V} \\
& \mu=0,54-\frac{42,6}{152,6+9,891 \mathrm{~m} / \text { menit }} \\
& \rightarrow \mu=0,2778
\end{aligned}
$$

Masukkan nilai koefisien gesek ke persamaan:

$$
\begin{aligned}
& 2,3 \log \frac{T_{1}}{T_{2}}=0,2778 \times 3,14 \\
& \log \frac{T_{1}}{T_{2}}=\frac{0,872292}{2,3} \\
& \log \frac{T_{1}}{T_{2}}=0,379257391 \\
& \frac{T_{1}}{T_{2}}=2,394 \rightarrow T_{1}=2,394 T_{2}
\end{aligned}
$$

Masukkan semua varabel yang didapat kedalam persamaan :

$$
\begin{aligned}
& \mathrm{P}=\left(\mathrm{T}_{1}-\mathrm{T}_{2}\right) \mathrm{V} \\
& 0,5652 \mathrm{KWatt}=\left(2,394 \mathrm{~T}_{2}-\mathrm{T}_{2}\right) 0,16485 \mathrm{~m} / \mathrm{dt} \\
& 0,5652 \mathrm{KWatt}=\left(1,394 \mathrm{~T}_{2}\right) 0,16485 \mathrm{~m} / \mathrm{dt} \\
& \mathrm{T}_{2}=\frac{0,5652}{0,2298}=2,459 \mathrm{Kg} \rightarrow \text { Tegangan } \\
& \text { sabuk pada sisi kendur } \\
& \mathrm{T}_{1}=2,394 \mathrm{~T}_{2}
\end{aligned}
$$

$$
\begin{aligned}
& \mathrm{T}_{1}=2,394 \times 2,459=5,886 \mathrm{Kg} \rightarrow \\
& \begin{array}{l}
\text { Tegangan sabuk pada sisi } \\
\text { kencang }
\end{array}
\end{aligned}
$$

\section{Bantalan}

Untuk mendapatkan ukuran dari bantalan poros perlu dilakukan perhitungan berdasarkan perhitungan terdahulu. Dengan ukuran diameter poros yang telah dihitung di atas dan bantalan hanya menerima beban radial, maka dipilihlah bantalan standar dengan nomor 6303.

Dari tabel standar untuk bantalan dengan nomor 6303 didapat datadata:

- Kapasitas nominal dinamis spesifik $(C)=1070 \mathrm{Kg}$

- Kapasitas nominal statis spesifik $\left(\mathrm{C}_{0}\right)=660 \mathrm{Kg}$

- $\mathrm{e}=0,27$

- Untuk pembebanan pada cincin dalam berputar, factor $\mathrm{V}=1$

Beban radial dapat ditentukan dengan:

Dimana

$$
\mathrm{Fr}=\mathrm{F}+\mathrm{W}_{\text {Poros }}+\mathrm{W}_{\text {Pulley }}+\mathrm{T}_{1}
$$

$\mathrm{Fr}=$ Beban radial $(\mathrm{Kg})$

$\mathrm{F}$ = Gaya pemecahan biji jarak (Kg)

$\mathrm{W}_{\text {Poros }}=$ Berat poros utama $(\mathrm{Kg})$

$W_{\text {Pulley }}=$ Berat pulley $(\mathrm{Kg})$

$\mathrm{T}_{1}=$ Gaya tarik sabuk sisi kencang $(\mathrm{Kg})$

Sehingga

$$
\mathrm{Fr}=12,5 \mathrm{Kg}+3 \mathrm{Kg}+0,27 \mathrm{Kg}+5,886 \mathrm{Kg}
$$$$
=21,656 \mathrm{Kg}
$$

sedangkan

$$
\begin{aligned}
& \frac{\mathrm{C}_{0}}{\mathrm{Fa}}=10 \\
& \mathrm{Fa}=\frac{\mathrm{C}_{0}}{15} \\
& \mathrm{Fa}=\frac{660}{15}=44 \mathrm{Kg} \\
& \frac{\mathrm{Fa}}{\mathrm{V} . \mathrm{Fr}}=\frac{44 \mathrm{Kg}}{1 \times 21,656 \mathrm{Kg}}=2,03 \\
& \frac{\mathrm{Fa}}{\mathrm{V} . \mathrm{Fr}}>\mathrm{e}
\end{aligned}
$$


maka didapat $\quad X=0,56$

$Y=1,64$

Faktor kecepatan (Fn) untuk bantalan

$$
\begin{aligned}
\text { bola } & =\left(\frac{33,3}{n}\right)^{1 / 3} \quad \text { Sehingga } \\
\mathrm{Fn} & =\left(\frac{33,3}{50 \mathrm{Rpm}}\right)^{1 / 3}=0,87 \mathrm{Rpm}
\end{aligned}
$$

\section{Beban Ekivalen Bantalan Radial (Pe)}

Menghitung beban ekivalen dari bantalan dapat dilakukan dengan menggunakan persamaan berikut :

$$
\begin{aligned}
& \mathrm{Pe}=\mathrm{V} . \mathrm{X} . \mathrm{Fr}+\mathrm{Y} . \mathrm{Fa} \\
& \mathrm{Pe}=1 \times 0,56 \times 21,656+1,64 \times 44 \\
& \mathrm{Pe}=84,287 \mathrm{Kg}
\end{aligned}
$$

\section{Menentukan Umur Bantalan (Lh)}

Untuk mencari umur pemakaian bantalan harus diketahui dulu faktor umur bantalan (Fh) dengan persamaan berikut :

$$
\begin{aligned}
& \mathrm{Fh}=\mathrm{Fn} \frac{\mathrm{C}}{\mathrm{Pe}} \\
& \mathrm{Fh}=0,87 \frac{1070}{84,287} \\
& \mathrm{Fh}=11,04
\end{aligned}
$$

Setelah didapat faktor umur bantalan, maka umur bantalan dapat dicari dengan persamaan berikut :

$$
\begin{aligned}
& \text { Lh }=500 F h(J a m) \\
& L h=500(11,04) \quad \text { (Jam) } \\
& \text { Lh }=672786,432 \text { Jam }
\end{aligned}
$$

Untuk bantalan bola nomor 6303 ditentukan

$$
\begin{array}{ll}
\mathrm{d}=17 \mathrm{~mm} & \mathrm{D}=47 \mathrm{~mm} \\
B=14 \mathrm{~mm} & \mathrm{r}=1,5 \mathrm{~mm}
\end{array}
$$

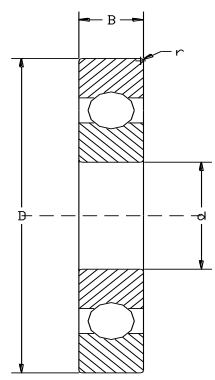

Gambar 6

Bantalan Bola

\section{KESIMPULAN}

1. Dengan dibuatnya mesin penggiling biji jarak ini, maka dapat mengurangi penggunaan tenaga manusia, guna meningkatkan kefektifan kerja agar tercapai produktifitas yang tinggi dibidang pertanian.

2. Dalam perencanaan rancang bangun alat ini, hal-hal yang perlu diperhatikan yaitu bentuk konstruksinya baru melakukan perhitungan tentang kekuatan untuk memilih bahan yang akan digunakan .

3. Berpegang dengan prinsip ekonomi, dalam memilih jenis bahan yang digunakan tiap-tiap komponen, biaya produksinya dapat ditekan sekecil mungkin tanpa mengabaikan perhitungan.

\section{SARAN}

Utamakan keselamatan kerja pada waktu pengoprasian mesin dan alat ini hendaknya dipergunakan sesuai dengan fungsi dan kapasitasnya

\section{DAFTAR PUSTAKA}

1. Sularso, Ir dan Suga Kiyokatsu, Prof, 1991, Dasar Perencanaan dan Pemilihan Elemen Mesin, Cetakan ketujuh, PT. Pradaya Pramita.

2. R. S. Khurmi J. K. Gupta, 1982, A Text Book Of Mechine Design, Euresia Languages Publishing House, (pvt) Ltd, Ram Nagar, New Delhi.

3. Nurcholis Mohammad, Dr. Ir. MAgr dkk, 2007, Jarak Pagar dan Pembuatan Boidiesel, Kanisius, Yogyakarta.

4. Sako G. Takeshi, 2001, Menggambar Teknik Mesin Standar ISO, Erlangga, Jakarta. 